\title{
GRUPO ESCOLAR “HUGO SIMAS”: CONSTITUIÇÃO HISTÓRICA, SUJEITOS E ALGUNS ASPECTOS DA ORGANIZAÇÃO DO TRABALHO PEDAGÓGICO (LONDRINA-PR, 1937- 1972) ${ }^{1}$
}

\author{
Thais Bento Faria ${ }^{2}$ \\ Universidade Estadual de Maringá (UEM) \\ Analete Regina Schelbauer ${ }^{3}$ \\ Universidade Estadual de Maringá (UEM)
}

\section{RESUMO}

$\mathrm{Na}$ condição de "representação hegemônica" de escola pública, o GE "Hugo Simas" cumpriu o ideário que acompanhou a difusão dos grupos escolares no período republicano? Por ser forjado em outro momento histórico, sob o predomínio do pensamento escolanovista, formulou novas práticas e incorporou vocábulos inspirados por esta corrente pedagógica? Este artigo, ademais de tentar responder a essas inquietações principais, busca identificar os sujeitos que fizeram a história desta instituição escolar e abordar alguns aspectos da organização do trabalho pedagógico. A análise de uma diversidade documental demonstra que o grupo escolar investigado se apropriou de alguns princípios escolanovistas embora conviva com práticas oriundas do fim dos oitocentos. Na busca de se firmar como uma escola de prestígio e qualidade, contava com um corpo docente composto majoritariamente de normalistas. Por se localizar em uma cidade que tem a diversidade étnica um de seus predicados, o "Hugo Simas" foi frequentado por número considerável de filhos de estrangeiros. Quanto à organização do trabalho pedagógico, percebe-se que era referência e sintonizado com os princípios de modernidade, racionalização, padronização e higienização.

Palavras-Chave: Instituições escolares; Escola pública primária; Grupo Escolar "Hugo

Simas".

\section{SCHOOL GROUP "HUGO SIMAS": HISTORICAL CONSTITUTION, SUBJECT AND SAME ASPECTS OF THE ORGANIZATION OF TEACHING JOB (LONDRINA-PR, 1937 - 1972)}

\begin{abstract}
As "hegemonic representation" of public school, did the "Hugo Simas" School Group fulfill the ideals that accompanied the spread of school groups in the Republican period? Being wrought in another historical moment, by the dominance of the New School, did the School Group formulate new practices and incorporated words inspired by this current teaching? This article, in addition to trying to answer these key concerns, seeks to identify the individuals who made the history of the school and address some aspects of the organization of educational work. The analysis of a variety of documents shows that school investigated the group took over some basics New School but live with practices from the end of the nineteenth century. Trying to establish itself as a school of prestige and quality, had a staff composed mostly of normalistas. It is located in a city that has the ethnic diversity of its predicates, "Hugo Simas" was attended by a large number of children of foreigners. About the organization of pedagogical work, that one was reference and attuned to the principles of modernity, rationalization, standardization and hygienization.
\end{abstract}

Keywords: School institutions; Primary public school; "Hugo Simas" School Group. 
Com o intuito de contribuir para a produção do conhecimento na área de História da Educação, no processo de revisão de literatura sobre a história da educação londrinense, constatamos a relevância de investigar a primeira escola pública primária - o Grupo Escolar Hugo Simas -, criada três anos após a fundação do município, em 1937.

Defrontamo-nos, portanto, com a seguinte problemática: na condição de "representação hegemônica" de escola pública, o GE "Hugo Simas" cumpriu o ideário que acompanhou a difusão dos grupos escolares no período republicano? Por ser forjado em outro momento histórico, sob o predomínio do pensamento escolanovista, formulou novas práticas e incorporou vocábulos inspirados por esta corrente pedagógica?

Diante deste problema de investigação, definimos como objetivo geral reconstruir a história e a memória da primeira escola pública primária londrinense, o Grupo Escolar "Hugo Simas", com o propósito de compreender a influência do ideário escolanovista em um projeto de escola arquitetado no final dos oitocentos. Como recorte temporal, delimitamos o estudo ao período que abrange desde o processo de institucionalização deste Grupo Escolar, em 1937, até o início da década de 1970, momento em que se torna Escola de $1^{\circ}$. Grau, com a aprovação da Lei de Reforma 5692/71 (BRASIL, 1971).

A reconstrução da história e da memória do Grupo Escolar "Hugo Simas" possibilitou entender, além de sua trajetória histórica, sua importância no processo de democratização da escolarização primária na cidade de Londrina, auxiliando na compreensão do seu papel no processo de criação e consolidação do município e, quiçá, nas reflexões pertinentes aos problemas da escola de ensino fundamental na atualidade.

Para tanto, reconstruir a história e a memória deste GE constituiu-se na meta principal da pesquisa, que se desdobrou em outros objetivos específicos ${ }^{4}$ de igual importância. Neste escrito, em especial, temos a finalidade de tecer alguns apontamentos sobre o processo de institucionalização do Grupo Escolar "Hugo Simas", adentrando no contexto de criação do município de Londrina; identificar o perfil do profissional da educação e dos educandos deste GE, bem como discorrer acerca de algumas práticas educativas.

Como assumimos a premissa de escola com autonomia relativa em diálogo com a realidade concreta e que, nesse processo, constrói sua identidade, a análise da escola esteve associada ao contexto macroscópico que a envolve, permitindo compreender o momento em que a instituição escolar se funda, o porquê torna-se necessária em determinado espaçotempo e seus antecedentes históricos, sempre em uma perspectiva dialética entre o particular e o geral, o singular e o universal.

Neste movimento de conhecer a totalidade e as partes, as partes e a totalidade, processo de conhecimento por excelência, configuramos a história deste grupo escolar. No início da investigação, poucas informações foram encontradas, apenas alguns registros em endereços eletrônicos, escritos da própria escola e referências curtas em livros que tratam da história de Londrina.

Todavia muito foi desvendado no contato com os diversos materiais do arquivo histórico da instituição. Documentos antes desconsiderados, como bem demonstra o panorama de pesquisas em torno das instituições escolares, hoje, são centrais para estudos similares a este. Faria Filho e Souza (2006) frisam que a atenção se volta para os documentos provenientes do interior da escola e foi para este espaço que centramos nosso olhar, para os documentos ali existentes.

Dentre as fontes documentais encontradas no acervo $^{5}$ do Grupo Escolar estavam: livros-pontos; termos de exercício; relatório do clube infantil; registro de aula de religião; relação de livros da biblioteca; livro de protocolo; registro de correspondência expedida; relação nominal; diário de atividades; registro de transferências recebidas e expedidas; 
livro de repreensão de alunos; livro de matrícula, frequência diária e aparelhamento escolar; livro de inventário material; recortes de jornal oficial; pastas de elástico com documentos soltos; relatórios supervisionados; livros didáticos; legislação de sociedade cooperativa; boletins informativos; livro de estatísticas; livros de aviso; escala de banca examinadora; notas bimestrais; relatórios finais; ofícios; registro de visitas; memorandos; atas diversas (exames finais, ocorrência, notas anuais, aprovações, conselho de classe, exame de consolidação, exposição escolar; reunião pedagógica, grêmios infantis, associações de mães, centro de professores), entre outros. (GRANDOLFI; LIMA; SANTOS, 2008).

Consideramos que, para adentrar no passado, é importante acessar os documentos produzidos: escrito, iconográfico, fonográfico e outras possíveis fontes. Como recomenda Le Goff (2003, p. 538), para que um documento contribua "[...] para uma história total, importa não isolar os documentos do conjunto de monumentos de que fazem parte". Significa que, ao romper com a supremacia de um documento sobre o outro, com a utilização de uma diversidade documental, o historiador pode cooperar para a construção de uma "história total".

Além das fontes escritas, encontramos as marcas do processo inicial de escolarização primária londrinense nas falas dos sujeitos que participaram e fizeram sua história junto ao Grupo Escolar "Hugo Simas", seus autores. Resgatar a memória de exprofessores e ex-alunos nos possibilitou entender a visão dos sujeitos envolvidos naquele evento histórico, proporcionou a compreensão do contexto investigado por ser capaz de dar voz aos sujeitos históricos.

No contato com o acervo da instituição e no encontro com os sujeitos pesquisados, deparamo-nos com fotografias. Como partimos de uma noção ampliada de documento, elencamos também as fontes iconográficas como mais um instrumento na coleta de dados.

Seja através dos documentos escritos, orais ou iconográficos, esta investigação se norteou em prol da reconstrução da história e da memória do Grupo Escolar "Hugo Simas", a primeira escola pública primária da cidade de Londrina-PR, que abordamos neste artigo.

Partindo da premissa que para tornar compreensível o que representou o GE "Hugo Simas" em seus primórdios só é possível frente ao cenário que o produziu, buscamos compor este espaço-tempo por meio da contribuição de historiadores, de documentos da instituição escolar e da narrativa de ex-professores.

Por intermédio de uma das notas publicadas pelo jornal "Paraná Norte" em 1934, Candotti (1997, p. 64), apresenta-nos alguns dados estatísticos que permitem ter uma visão acerca do crescimento deste município no período de 1931 a 1934.

O crescimento em termos de construções, também evidenciava um adensamento populacional na zona urbana, no entanto, tal crescimento, ainda não foi suficiente para superar a população rural, tendo em vista que o crescimento desta se deu em função de uma economia agrícola predominante. Arquitetonicamente, o que se construiu naquele momento foi uma "cidade de madeira".

O desenho urbanístico em expansão retratava um município oriundo pela economia agrícola, utilizando-se de materiais disponíveis na natureza. Apesar desse crescimento urbano, não houve naquele momento a superação do crescimento rural, cujas culturas agrícolas mais desenvolvidas foram o arroz, o algodão, o feijão, o milho, entre outros produtos. Só em 1936, surgiram as primeiras tentativas de produzir café, cultura que alcançou o seu apogeu na década de 50. (CANDOTTI, 1997). 
Londrina tinha como marca de seu progresso suas terras férteis e a produtividade que proporcionava. Razões pelas quais seduziram pessoas de diferentes nacionalidades e outras já fixadas nos demais estados brasileiros sentiram-se seduzidas. A oportunidade de se tornarem proprietários de terras e enriquecerem os trouxe a esta cidade.

Não se pode esquecer que o município se originou como um empreendimento imobiliário e, por estar sob o comando de uma empresa colonizadora, diversas instituições e estabelecimentos foram construídos mediante doação de terrenos pela Companhia de Terras Norte do Paraná. (CANDOTTI, 1997).

E por acreditar que a escola coincidia com "progresso", a Companhia favoreceu diversas iniciativas educacionais, dentre elas a construção da primeira escola pública primária em Londrina.

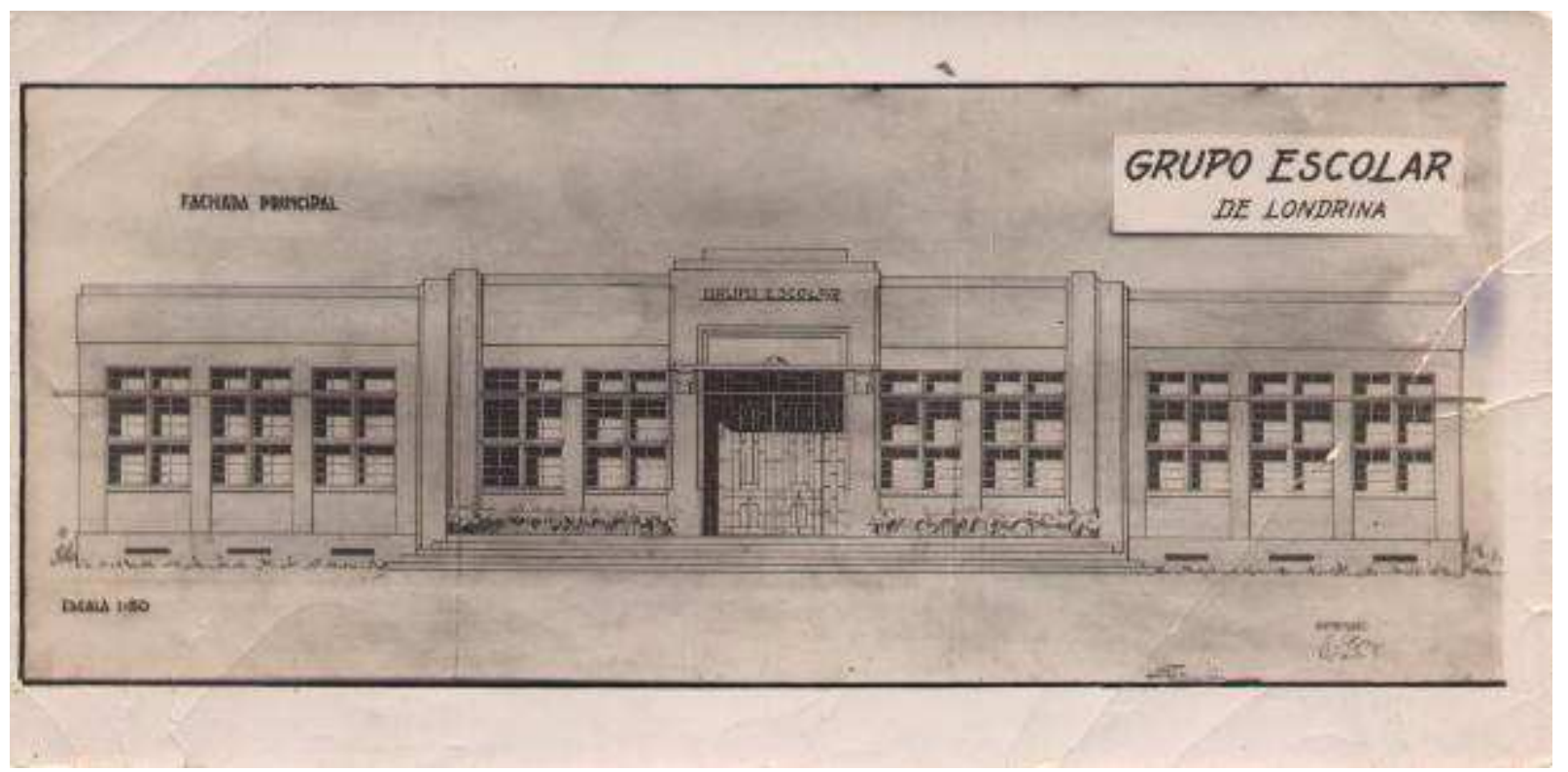

Ilustração 1 - A planta da construção do Grupo Escolar.

Fonte: Acervo Fotográfico: Colégio Estadual "Hugo Simas", [193-].

Da precariedade e ausência de espaços públicos de ensino, projetou-se uma arquitetura que trazia em seu cerne a modernidade, a disciplina e a racionalização do uso dos espaços escolares. Como pode ser observado na planta do Grupo Escolar:

[...] construído em alvenaria, com salas amplas, trazia a funcionalidade como tema principal. As salas se interligavam ao corredor principal a diretoria e a secretaria, foram projetadas para ocupar a entrada do prédio, um meio considerado eficiente para controlar a entrada e a saída dos alunos em tempos de rigorosa disciplina. A obra surtiu grande efeito e foi bastante apreciada pela população como a materialização dos desejos de modernidade, levados aos extremos pelos londrinenses. (ABRAMO, 2004, p. 58).

Reiteramos: uma obra que inspirava modernidade, disciplina e poder aparece como características desta primeira benfeitoria pública em Londrina. Como descreve a autora, o contorno do espaço destinado ao aluno, bem como o da administração escolar cumprem a finalidade de controlar o interior da escola.

A implantação do primeiro edifício público municipal para instalação do Grupo Escolar coincide com a era Vargas (1938-1939), em que havia um forte movimento de 
nacionalização compulsória e decretos que ordenavam o fechamento de escolas étnicas ou sua transformação em escolas públicas, como ressalta Kreutz (2000).

Embora bem mais difundida na década de 1930, essa discussão já ocorria. No Paraná, em 1909, o deputado governista Hugo Simas apresentou um projeto que objetivava nacionalizar o estrangeiro. Interessante observar que o primeiro Grupo Escolar Londrinense recebe o nome do deputado paranaense.

É importante salientar que em 1918, este projeto voltou a ser debatido em função do Decreto Federal n. 13.014, que determinava o auxílio em dinheiro para as instituições públicas para o ensino de língua portuguesa, geografia e história do Brasil nos municípios formados por antigas colônias de europeus. A nacionalização do estrangeiro vinculava-se ao fortalecimento da unidade nacional. Era a necessidade de integrar esses imigrantes à vida da nação brasileira, de maneira que seus anseios futuros se relacionassem "[...] à nova pátria e não ao país de origem". (SCHELBAUER, 1998).

Temos, destarte, medidas sendo executadas em nível nacional, regional e local com o mesmo desígnio. Entretanto, os cumprimentos de decretos só aconteceriam por intermédio de instituições capazes de fiscalizar e de fazer valer as normatizações propostas. O GE "Hugo Simas" veio a ser este órgão governamental na comunidade londrinense. A escolha do nome do homenageado e o contato com documentos produzidos no seu interior certificam o papel de fiscalização e controle exercidos pelo estabelecimento de ensino.

Ilustrativo é o fato de que, em 1937, o diretor do GE "Hugo Simas", Antenor Henrique Monteiro, pediu ao Delegado Regional de Ensino “[...] instruções para com o grande número de Escolas particulares estrangeiras que existe neste município sendo que nenhuma delas preenchiam as formalidades exigidas pelas leis de Ensino [...]”. (COLÉGIO ESTADUAL HUGO SIMAS, 1937-1941, p. 1).

Como este, localizamos também outros ofícios que evidenciam sua função de comunicar a situação das demais escolas londrinenses, fossem elas isoladas rurais e urbanas, particulares da zona urbana ou particulares étnicas.

Pelos escritos, observa-se que, nesse momento, ao GE "Hugo Simas" competia a fiscalização, envio de comunicados aos órgãos superiores de ensino e era dado a ele o poder de atuação para que as normatizações nacionalistas se concretizassem. Esclarecedor também é a frequência de informativos acerca da educação ofertada por estrangeiros em seus lares ou instituições fundadas por eles. (COLÉGIO ESTADUAL HUGO SIMAS, 1937-1941).

Sob a era Vargas, num movimento intenso de nacionalização, a cidade, composta pela multiplicidade étnica, teve de articular meios para unificar o diverso. O GE "Hugo Simas", como se pode notar, exerceu relevante papel no atendimento a uma parcela de escolares e, boa parte de sua constituição, foi o "olho" do Estado ao fiscalizar as demais instituições para o cumprimento das normatizações decretadas.

Denunciou escolas étnicas que persistiam em propagar sua língua, apreendeu materiais de ensino, avaliou o desempenho escolar de instituições particulares, distribuiu materiais para as escolas isoladas, demais grupos escolares e escola normal, dentre outras iniciativas que indicam o papel central desta instituição de ensino. Observamos que, ademais de atender a uma significativa quantia de alunos, colaborou com a constituição do ensino primário de Londrina. Foi agente fiscalizador, provedor e também modelar para as outras escolas elementares, já que as "novidades" no campo pedagógico se difundiam por intermédio dele. 
A fim de compreender também quem eram os sujeitos que fizeram a história desta instituição escolar, questionamo-nos: mas quem eram os meninos e as meninas desse grupo escolar e quem eram seus professores?

Acerca do alunado procuramos responder questões específicas, tais como: qual a localidade de procedência dos alunos? São residentes da zona rural ou urbana? Se declarados brasileiros, qual sua descendência paterna? E a idade, qual a variação existente em cada uma das séries?

No que tange à procedência dos discentes, uma parcela significativa era originária do espaço urbano e, no decorrer dos anos, houve uma queda abrupta, até quase inexistência de alunos provenientes da zona rural. Dos que declararam endereço residencial urbano, em 1937, 1941, 1951, 1961 e 1971, obtivemos o percentual aproximado de, respectivamente: $76 \%, 81 \%, 87 \%, 99 \%$ e $100 \%$. Além da maioria dos alunos residirem na cidade, era recorrente o nome de ruas centrais e, repetidas vezes, apareciam referenciados algumas vilas e os mesmos locais do meio rural.

Estas informações comprovam que o GE "Hugo Simas" se dedicava, desde seus primórdios, majoritariamente à educação dos citadinos. No entanto, por que diminuiu o número de alunos provenientes da zona rural? Ademais da possível mudança de endereçamento, com a migração do espaço rural para o urbano, alguns apontamentos são importantes. Entre os anos 1950 e 1960, disseminaram-se escolas rurais. A justificativa para sua instalação, encontramos em Capelo (2000, p. 54-55).

[...] a instalação de escolas nas fazendas passou a ser, por vezes, uma exigência dos proprietários [...] A escola rural, até o final dos anos 60 não parava de proliferar, percorrendo os caminhos traçados pelas famílias que trabalhavam nas lavouras de café e compradores de terras. As demandas por escolas rurais crescem substancialmente até os primeiros anos da década de 70. Entretanto, em meados dessa década, já se começa a verificar os dissabores do esvaziamento do mundo rural.

Conforme a autora, a educação se tornou um mecanismo de fixar o homem no campo, particularmente depois da Segunda Guerra, com a proliferação de novas práticas domésticas e agropecuárias, as quais aumentariam a chance de maior produtividade e de melhorar sua condição de vida.

Com esta finalidade, proliferaram-se as escolas rurais nas décadas de 1950 e 1960, em Londrina. À medida que atendia esse público, menos crianças tiveram que se deslocar até o Grupo Escolar "Hugo Simas" e, assim, este se consagrou como uma instituição exclusivamente responsável pela educação dos citadinos.

Outro ponto analisado foi que, nos anos 1950 e 1960, como demonstra Arias Neto (1998), houve um violento êxodo rural decorrente da crise do café, da implantação de culturas que se utilizavam da mecanização agrícola e da intensa concentração de terra. Iniciou-se, destarte, um processo de favelização e com isso surgiu o trabalhador volante, que mora na cidade e trabalha no campo, alterando a porcentagem populacional. Em 1970, $68 \%$ dos londrinenses se concentravam no meio urbano e $32 \%$ na área rural.

Essa inversão traçou um novo desenho urbanístico de Londrina e especificou qual o público desse GE, entretanto esse público não era formado pelos filhos do popular "bóiafria". Nos anos setenta, são os residentes dos arredores da escola e, por insistência de alguns, também alunos oriundos de vilas, que buscavam uma instituição de referência.

O relato de uma professora que atuou nos anos de 1960 confirma a mudança de perfil do alunado no GE investigado. 
Agora não é o mesmo, porque tudo mudou. Aí houve interferência das crianças de lugares distantes prá vir prá o Hugo Simas, porque era um Grupo que tinha conforto, tinha material escolar, tinha alimentação [...] A merenda escolar era muito boa; então, as crianças, as mães, solicitavam, pediam prá pôr as crianças dos bairros distantes no Hugo Simas, aí que houve uma transformação. (SANTOS, 2009).

Constatamos a mudança gradual do público atendido pela escola primária, bem como uma maioria de descendentes de estrangeiros. Por ser característica de Londrina a multiplicidade étnica, entre as décadas de 30 e 70 do século XX, nos livros de matrícula do GE "Hugo Simas", há o registro de descendentes de japoneses, italianos, espanhóis, portugueses, alemães, sírios, poloneses, russos, gregos dentre outros.

Apesar de a maioria se autodeclarar como brasileiros, 94\% em 1937, 74\% em 1941, $60 \%$ em 1951, 81\% em 1961 e $92 \%$ em 1971, o percentual registrado na década de 1930 é questionável, à medida que Londrina se compunha por uma considerável população de imigrantes e a expectativa era que esse número aumentasse gradativamente, o que não se nota na transição de 1937 para 1941. Explica-se este fato, porque, frente ao forte movimento nacionalista da época, não se autodeclarar "brasileiro" seria uma afronta e, talvez, um impedimento para garantir uma vaga nos estabelecimentos públicos de ensino.

Embora apresente uma significativa quantia de filhos de europeus depois dos declarados brasileiros, a maior parte era de descendentes de japoneses: $4 \%, 16 \%, 27 \%, 14 \%$ e $4 \%$, nos respectivos anos acima citados. Estes residiam em distintos locais: em um Pensionato Japonês, no meio rural e também na cidade. (COLÉGIO ESTADUAL HUGO SIMAS, 1940-1942).

A maciça presença de japoneses é corroborada igualmente nos retratos de diplomados nos anos de 1945 a 1947, contrastando com o diminuto número de negros. Ao atender majoritariamente o filho do trabalhador urbano, o citadino e o estrangeiro, compreendemos que o "Hugo Simas" desempenhou a função de aculturar, homogeneizar as diferentes culturas e, portanto, abrasileirar o estrangeiro.

No que concerne aos profissionais que trabalhavam no Grupo Escolar "Hugo Simas", levantamos alguns questionamentos, sobretudo almejamos saber qual sua formação inicial.

Memorandos e Termos de Compromisso talvez respondessem as indagações, não obstante, nestes, nem sempre constavam a formação prévia. Livros-ponto e outros escritos também auxiliaram neste processo de recompor o perfil da professora desta primeira escola pública primária de Londrina.

A insistência e a escolha por usar sempre o substantivo feminino ao nos referirmos ao profissional da educação justificam-se pelo contato com os dados concretos sobre a questão de gênero nesta escola primária. Em 1939, apenas um, o diretor Aristeu Costa Pinto, era do sexo masculino, as demais eram mulheres. Um corpo docente majoritariamente feminino também se apresentou entre as décadas de 40 e 70. 


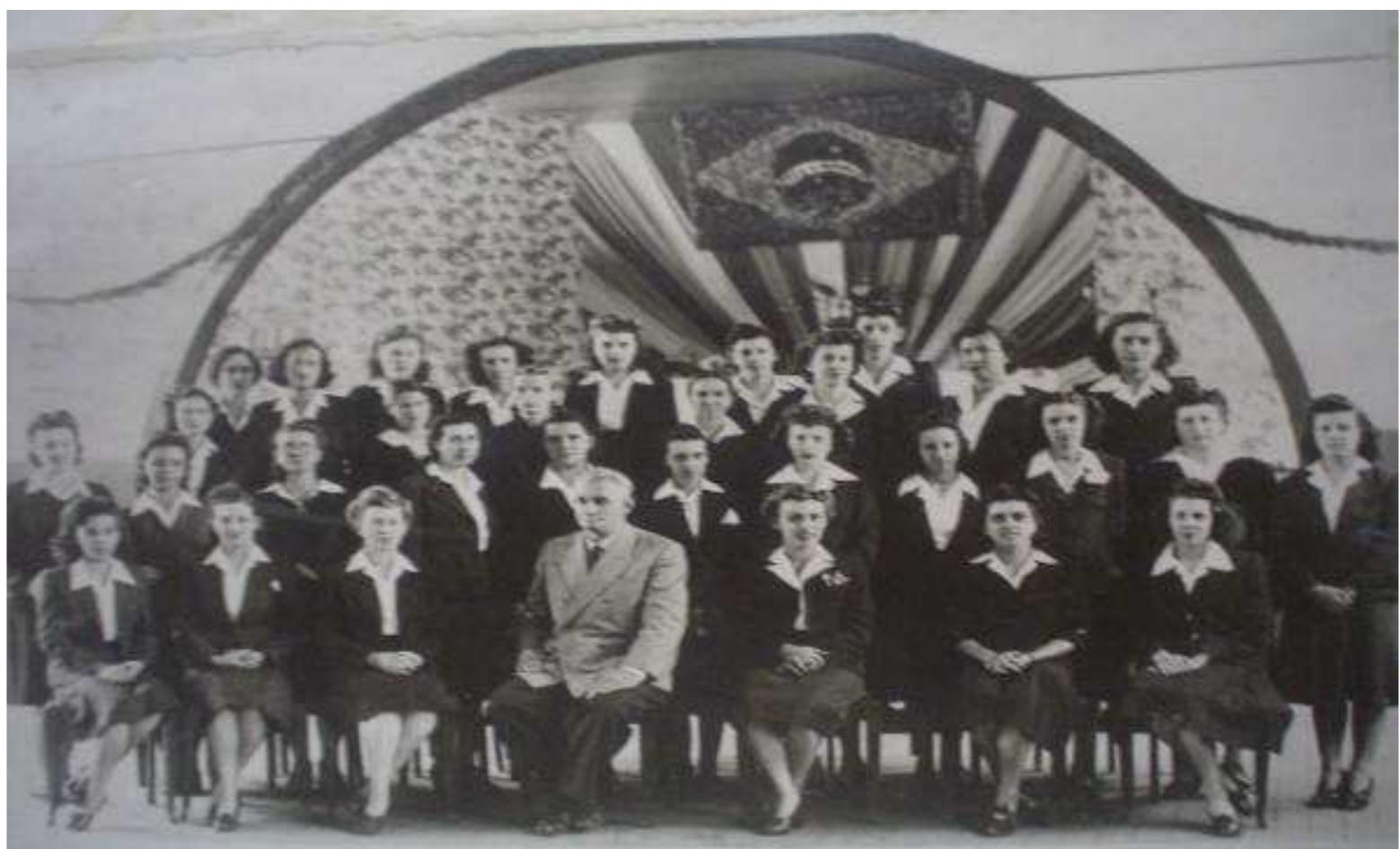

Ilustração 2 - Corpo docente do Grupo Escolar "Hugo Simas" e o Delegado do Ensino, ao seu lado direito, a diretora Mercedes Camargo Martins.

Fonte: Acervo Fotográfico. Colégio Estadual "Hugo Simas" (Diplomandos de 1945).

A foto confirma o fenômeno da feminilização do magistério nesta instituição escolar, que se fortificou desde o fim do século XIX, pela necessidade de ter um significativo número de profissionais encarregados da difusão da educação popular. Alicerçada na moralidade, as mulheres eram as principais indicadas para "[...] modelar uma infância saudável, patriótica e livre de vícios que degeneram a raça e a sociedade". (ALMEIDA, 2006, p. 75).

Era também a oportunidade de inserção em um dos primeiros campos profissionais de prestígio para a figura feminina, contextualiza Souza (1998), e foi o que ratificaram as docentes entrevistadas que atuaram no GE "Hugo Simas".

Além da feminilização da atividade educativa, o papel hierárquico e a importância das normalistas eram evidentes, uma vez que o registro de frequência no livro-ponto demonstra que as assinaturas se apresentavam pelo grau de importância dentro da instituição, primeiramente assinava o diretor, seguido das normalistas e, por último, os demais profissionais.

Desde a concepção do GE "Hugo Simas", as normalistas representaram a maioria das professoras desta instituição. Já em 1939, 42,8\% do professorado tinha formação na escola normal. Nas décadas de 1940 e 1950, manteve praticamente o mesmo percentual. Em 1961, num total de 80 professoras, 72 eram normalistas, ou seja, o equivalente a $90 \%$. Em 1972, considerando apenas as regentes de classe, das 42 professoras, três haviam concluído um curso superior, as demais possuíam Normal Colegial e 12 docentes já cursavam uma faculdade.

Este significativo avanço no que se refere à formação docente aconteceu devido ao aumento de instituições formadoras. Só para mencionar algumas, na década de 1950, o Colégio Mãe de Deus iniciou a oferta do Curso Normal e, com a proliferação da Escola Normal Regional pelo Paraná, esta modalidade de ensino também se instalou em Londrina. 
No decorrer das décadas de 1930 a 1970 o número de professores se expandiu, uma vez que ampliar o acesso da população londrinense ao ensino primário era uma necessidade. Além disso, mesmo em um momento em que eram escassos profissionais com uma titulação específica, o GE "Hugo Simas" apresentava um expressivo número de normalistas, quantia que aumentou ao longo das décadas.

Compreendemos este fato pelo desejo de ali trabalhar devido ao público atendido, sua localização e reconhecimento obtido junto à comunidade local. Da mesma forma, por ser a figura do Estado em um município que nasceu a partir da iniciativa privada, era primordial um quadro de funcionários com titulação a fim de se tornar modelo às demais escolas.

A importância da figura da normalista e seu reconhecimento social também se explicitam na diferença de salários. Informações datadas de 1951 mostram uma oscilação de vencimentos mensais de acordo com a formação docente: uma normalista recebia entre $1.800,00$ e 1.400,00 cruzeiros e, sem este curso, entre 900,00 e 800,00 cruzeiros. (COLÉGIO ESTADUAL HUGO SIMAS, 1950-1952).

Mais do que estes números representam, ao puxar pela memória das antigas docentes, elas evidenciaram uma nítida satisfação em ser professora e o prestígio social atribuído à figura docente desta instituição. Assim testemunha Prata, professora nos anos de 1960:

Quando ia à igreja jamais eu fiquei em pé, sempre alguém te oferecia o lugar. Quando chegava Dia dos Professores, o dia disto ou daquilo, eram os presentes ... Não que você fizesse questão disto, não era isso, mas era uma tradição. Mesmo os mais simples [...]. Coisas que você não esquece: era uma flor, era uma gentileza, era um perfume, era um chocolate, era um tecido [...] (2009).

Penteado (2009) também relata o prazer de ser docente, o que este grupo escolar representava para a sociedade londrinense e a escolha do professor pelos pais dos alunos.

Nesta época, escola mesmo, o Hugo Simas era uma referência, todo mundo estudava lá no Hugo Simas, não tinha, não tinha é... outras escolas de nível tão bom como era o Hugo Simas, então todas as famílias estudavam lá. Tem família aqui que eu alfabetizei do primeiro ao último filho. Então vinha o primeiro, depois vinha o outro, vinha o outro, vinha o outro... Me lembro que uma vez, uma menininha chamada Cecília, o pai dela era médico, ela disse assim: a minha mãe mandou falar prá senhora que hoje nasceu, nasceu o Jorge e é prá senhora guardar um lugar prá ele na sua classe. No dia do nascimento do neném. E olha, pensei: 'mas será que eu vou ficar até o Jorge crescer?' Pois o Jorge cresceu, passou por mim, se formou e hoje é um homem, um engenheiro em São Paulo.

Uma escola de referência, em que "[...] antes da criança nascer escolhia-se a professora", brincadeira mencionada por outra professora que autentica a narrativa anterior. Tratava-se de uma instituição projetada com a finalidade de ser modelo educacional, que só se firmaria como tal se tivesse professores com formação compatível à simbologia que se propunha exercer.

O que simbolizava, a localização, o reconhecimento societário em ser docente nesta escola primária de estrutura imponente para a época, isso tudo se tornou um atrativo para os profissionais mais qualificados, que já possuíam uma formação prévia. 
Abordamos um pouco da história de Londrina e intentamos retratar os sujeitos que compunham esta instituição educativa. Abaixo buscamos elucidar como que se organizava o trabalho pedagógico, sobretudo, centramo-nos na identificação do pensamento educacional em vigência nas décadas investigadas, ou melhor, percebemos como coexistiram modelos contrastantes e estes eram "conciliados" pelos educadores.

\section{Organização do Trabalho Pedagógico: a coexistência de modelos educacionais}

Como as ideias circulam, os ideais do movimento da Escola Nova também se incorporaram às práticas das instituições escolares ou, ao menos, tornaram-se fonte de discussão e reflexão. Na leitura e análise de atas das reuniões pedagógicas, de um Diário de Classe e por meio das falas de professores daquele período e outros escritos, identificamos o quanto o discurso escolanovista adentrou os portões do GE "Hugo Simas", considerando que o ano de sua fundação - 1937 - corresponde ao período que ocorreu o ápice deste ideário.

Os primeiros registros em ata de reunião pedagógica localizados são datados de 1941, neles há aproximações com o que se tinha de mais "moderno"6 relacionado aos métodos de ensino. Ademais da busca pela disciplina, ordem e informes sobre eventos extraescolares, a discussão sobre o como ensinar e proceder em sala permeava os encontros do professorado dessa instituição.

Considerando que várias reuniões exibiam aulas modelo, não foi difícil conferir o que era recomendado ou refutado na década de 1940 no que se refere ao método de ensino no Grupo Escolar "Hugo Simas". Após a explanação da aula, as docentes encarregadas de fazer a crítica observavam se o método de ensino estava em harmonia com a Nova Pedagogia, bem como com o programa de ensino e se haviam sido utilizadas ilustrações. (COLÉGIO ESTADUAL HUGO SIMAS, 1941-1942).

O comportamento adotado pelas docentes se delineava por princípios de disciplina e ordem, além de que se manter "ativas" era uma exigência, como bem demonstra o informe abaixo.

[...] a sra. diretora comunicou ás sras. professoras que obedecessem os parágrafos $11^{\circ}$, que pró́be o prof. de "permanecer sentado durante o horário integral consignado a cada aula, pois desse modo as mesmas deixarão de ser ativas e procedentes", e o $13^{\circ}$ de "fazer comentarios deprimentes ao trabalho, processuação e métodos executados em outras classes", do artigo $7^{\circ}$ do Regimento Interno acima citado. (COLÉGIO ESTADUAL HUGO SIMAS, 1941-1942, p. 6-verso).

No que tange à determinação do parágrafo $11^{\circ}$, esta orientação foi mantida ao longo da história desse grupo escolar. O relato de uma professora, que trabalhou na década de 60 do século XX, menciona que a Dona Mercedes sempre dizia: "Boa professora não tem cadeira prá sentar!". (PRATA, 2009).

Apesar de termos tido mais acesso às discussões metodológicas datadas dos anos 1940, demais escritos apontam que há uma amálgama entre os "métodos mais tradicionais" e o "moderno" discurso escolanovista, ratificado também no contato com um diário de classe.

O diário localizado é uma amostra do dia-a-dia em sala de aula de um período, o mês de agosto de 1969. Com ele nasce a possibilidade de manusear e analisar como se dava a prática do ensino em uma das turmas do GE "Hugo Simas". Este, entrelaçado com 
as memórias de docentes dos anos 40 a 60 do século $\mathrm{XX}$, forneceu indubitavelmente elementos relevantes para analisarmos a prática escolar.

É um caderno com anotações detalhadas do planejado para a turma, minucioso, tem observações em sua lateral, contém "todos" os exercícios propostos em sala e organiza, separadamente, as disciplinas de português, aritmética, estudos sociais e religião. No Diário, evidenciamos o emprego frequente de materiais concretos e de ilustrações.

Quanto ao material didático referente ao nôvo ponto a ser dado hoje, usarei figuras no flanelógrafo, e desenharei no quadro, com giz colorido, para as crianças desenharem em seus cadernos. Isto, porque, tudo que se aprende com ilustração, desenho e ordem, fixa-se melhor e a aprendizagem torna-se mais eficiente. (COLÉGIO ESTADUAL HUGO SIMAS 1969, p. 14).

Desenhos que também se associam aos questionários e à explanação da aula: "Darei o ponto com desenhos. Êstes aparecerão junto com o questionário". (COLÉGIO ESTADUAL HUGO SIMAS 1969, p. 4-verso). Sua utilização não se restringe a esses momentos, aliava-se às anotações do diário, que é todo ilustrado. $\mathrm{O}$ trabalho de pesquisa não pôde deixar de ser registrado, pautar-se nele é habitual, vejamos:

Como trabalho de pesquisa, pedirei aos alunos que tragam figuras e pequenas reportagens sôbre a "Apolo 11" e a conquista da lua; quero, juntamente com eles elaborar cartazes a respeito. Dêste modo, maior será o interesse, e, assim sendo, aproveitarei êste assunto tão atual para ser alvo, ou melhor, o centro de interesse desta semana.

Irei relacionar todas as matérias, na medida do possível, com o assunto já referido. (COLÉGIO ESTADUAL HUGO SIMAS 1969, p. 5).

Partir do interesse dos educandos é, por muitas vezes, aludido como essencial, assim como o trabalho de pesquisa e o centro de interesse são referenciados em alguns momentos. A atualidade do tema, a ida do homem à Lua, era o que tornaria motivadora a aula, ideias que se arraigaram e se transformaram em prática de ensino.

A recapitulação do aprendido mediante atividades escritas e algumas orais; imagens e conteúdos vinculados ao catolicismo nas aulas de religião; a tarefa como exercício diário; problemas matemáticos que envolviam situações cotidianas de compra, venda, lucro e prestações; a presença do princípio "conhece-se do simples ao complexo", haja vista a gradação do conhecimento nos exercícios; o destaque aos hábitos e atitudes que seriam ensinados e o cantinho da novidade também eram uma constante nesse Diário de Classe.

A ligação da prática educativa desse grupo escolar com princípios da Escola Nova também se mostra nas falas das professoras entrevistadas. Cosentino (2009), docente na década de 1940, descreve uma de suas aulas: na "[...] aula de sábado, eu convidava uma profissão, veio o pai de um aluno que era jardineiro e fazendo jardins e explicando prá eles e eles participaram. Depois, no outro sábado, [...] o pintor é que deu trabalho [...]". Conta, ainda, sobre a pintura do porão e de alguns armários da escola pelos alunos.

Narra outras inovações presentes em sua prática escolar:

A gente usava livro, tinha uma vitrola, eu levava disco, tocava histórias... Pesquisa, principalmente, todo dia tinha que trazer alguma coisa, descobriram até quem foi que inventou o guarda-chuva. [...] e no meu quadro tinha que ter alguma coisa nova, da época. (COSENTINO, 2009). 
Ter como positivo o que é "novo" é vislumbrado na narrativa desta professora, o mesmo se percebe duas décadas depois no Diário Escolar de 1969 e na fala de outra docente. Esta, ao descrever uma aula típica, expõe que solicitava tarefa todos os dias, exceto nos fins de semana, iniciava a aula com correção de tarefa, "reforçava" a aula dada ou apresentava uma nova matéria por meio de uma "fala mais entusiasmada", com o uso de desenhos, giz colorido, recortes ou experiências... Enfatiza que: "Eu sempre fui 'inovidaderia"” e que "todo dia você tinha que estar inovando". (PRATA, 2009).

Em contrapartida, corrobora-se a sobrevivência do "moderno" com o "antigo". Relata Penteado (2009) que chegava uma hora antes na escola e, no pátio, com os alunos em fila, "tomava lição" de todos. Quando entrava na sala, já tinha 'tomado a lição', corrigido o dever de casa e iniciava a matéria daquele dia.

\footnotetext{
Aí era feito uma leitura na lousa, era passado todo dia, você passa aquela leitura [...] hoje é só as vogais, então é só as vogais, quando eu entro no B eu repito a lição de cá e passo na lição de lá [...] fazíamos a leitura oral da classe toda [...] depois desta leitura era feito o ditado [...] e não podia deixar, a Dona Mercedes não admitia que auxiliar ajudasse na correção, a gente tinha que ditar e olhar, não deixar a criança escrever errado porque se ele escreve uma vez errado depois é muito mais difícil você ensinar escrever certo [...].
}

Completa que: em seguida ao ditado, era o momento da leitura silenciosa, do exercício de gramática... Diariamente, era essa rotina até alfabetizar, a preferência era a aula de alfabetização, depois, o ensino da matemática. A criança aprendia com a maior facilidade, contudo sob muito trabalho docente e dedicação, exemplo disto são os cadernos com exercícios passados à mão, pois nem havia mimeógrafo. (PENTEADO, 2009).

Por estas falas e escritos, notamos a convivência de práticas "modernas" com as ditas "tradicionais", ou seja, coexistiam modelos e práticas educacionais, uns oriundos do fim dos oitocentos e, outros, procedentes dos novecentos. Entretanto a empolgação ao citar práticas "inovadoras" denota a supremacia desta em detrimento do que era considerado "tradicional".

O intento era superar alguns modos de fazer escola e ter como prática a inovação, o emprego de experiências, o "aprender fazendo", o uso de materiais diversificados para atrair a atenção discente, a relação dos saberes escolares aos diários, a pesquisa, entre outras que elucidam a incorporação do escolanovismo e seus ideais na prática ordinária do Grupo Escolar "Hugo Simas", entre as décadas de 1940 e no final da de 1960.

\section{Algumas considerações...}

Percebemos nessa investigação que a representação de "instituição primária de referência" convivia com o problema de atender à demanda escolar. A dificuldade de universalizar o ensino primário fez com que realizasse o que era emergencial: homogeneizar o diverso. Unificar aqueles que reocupavam o município por meio da transmissão da língua, da veneração de seus "heróis" e de seus símbolos, da demarcação do que era para se tornar inolvidável.

Ao atender majoritariamente o filho do trabalhador urbano, o citadino e o estrangeiro, compreendemos que o "Hugo Simas" desempenhou a função de aculturar, homogeneizar as diferentes culturas e, portanto, abrasileirar o estrangeiro.

Com esse desígnio, momentos eram dedicados para isso: desfiles, exposições de trabalhos, atividades pedagógicas, respeito aos símbolos e importância aos rituais. A 
formação do "povo londrinense" acontecia à medida que o GE "Hugo Simas" formava uma mentalidade menos contrastante.

Objetivando ampliar o número de alunos, esta escola primária pública utilizou como alternativas o desdobramento de turnos e, em alguns momentos, o uso de outros espaços. E, sob os ideais escolanovistas, a dificuldade se encontrava na constituição de locais para abrigar as instituições auxiliares e ter profissionais em número suficiente para atuar nesses espaços.

Os empecilhos para a materialização do propagado pela Escola Nova também se mostraram na insuficiência material do GE "Hugo Simas". Apesar de estar mais bem equipado do que as escolas isoladas, as falas das entrevistadas registram que, pelos recursos disponíveis, era preciso ter criatividade e o cotidiano escolar ser permeado de muito trabalho e dedicação. A grandeza e o reconhecimento social adquirido pelas profissionais que ali atuaram quiçá tenham nestes fatores uma das justificativas.

Por termos como premissa o conceito de escola com autonomia relativa, que está imersa em um contexto, é influenciado por ele e também faz cultura, movimentar-se entre o universal e o particular foi um exercício constante. Desta forma, simultâneo ao movimento de inserção no tempo e espaço em que se projetou o GE "Hugo Simas", propusemo-nos a perceber permanências e mudanças na prática de ensino em seu interior.

Dentre as permanências podemos frisar: os princípios que nortearam o método de ensino intuitivo eram ainda utilizados na prática pedagógica; nota-se a falta de autonomia docente e a preocupação com o cumprimento do programa; cartilhas, mapas, cadernos, livros de leitura, bandeiras e demais símbolos patrióticos resistiram ao tempo e se consolidaram como instrumentos permanentes de ensino; o pacto com o ensino religioso, em especial com o catolicismo, representa mais uma das medidas homogeneizantes; tal como nos grupos escolares projetados no fim dos oitocentos, tinha como atributo a seletividade e o rigor no processo de avaliação, explicitados nos altos índices de reprovação; verificou-se a supremacia da linguagem escrita e do ensino da matemática em detrimento das demais disciplinas curriculares; as exposições escolares, sobretudo com as exibições dos trabalhos manuais, constituíram-se em um modo de se mostrar a sociedade; mesmo considerando o interesse infantil, o que verificamos é o professor no centro do processo de ensino e aprendizagem.

A reconstrução da história e da memória desta instituição primária, igualmente, evidencia as alterações ocasionadas com a disseminação dos ideais escolanovistas mediante:

- a presença do "aprender fazendo" nas exposições de aulas-modelo e em algumas práticas de ensino;

- o relativismo metodológico para o ensino da leitura e de outras disciplinas curriculares;

- o estímulo ao uso de metodologias que despertassem o interesse infantil, como o teatro e o jogo;

- a criação de instituições auxiliares: biblioteca infantil, jornal infantil, cooperativa, clube agrícola, associação de pais e mestres, etc. Uma forma de aproximar a ação educativa escolar do meio social, expandir seu campo de atuação e de intervenção social;

- a inclusão de acervo bibliográfico que propagava o pensamento da Escola Nova;

- a pesquisa, o interesse do educando, a inovação como prioritários e manter-se "ativas" como recomendação para todo o fazer pedagógico;

- o processo de ensino pensado "sob medida", explicitado na divisão das turmas nas avaliações finais. 
Ademais da influência deste pensamento pedagógico, as práticas ordinárias do "Hugo Simas" estiveram em sintonia com o projeto desejável de cidade, em especial na tentativa de higienizar, civilizar e unificar. Contribuiu para a formação da classe dirigente londrinense e de profissionais que atuariam nas atividades urbanas, assessorando o desenvolvimento desta cidade.

A reconstrução da história e da memória do Grupo Escolar "Hugo Simas", além de responder a questão que norteou nossa pesquisa, proporcionou refletir acerca dos problemas da escola de ensino fundamental na atualidade e fazer algumas inferências.

Ainda persiste e exige soluções, a disparidade de recursos materiais e humanos entre escolas públicas centrais e periféricas. Enquanto, em algumas, modernos instrumentos de ensino são adquiridos, as que se edificaram para aqueles que estão fora do projeto inicial da cidade, gasta seus parcos recursos com a aquisição de materiais mínimos para o exercício docente.

No contato com a realidade escolar, sem afirmar com dados precisos, notamos que, pela distância e pelas condições sociais do público das escolas periféricas, estas sofrem com a rotatividade de profissionais, o que, indubitavelmente, interfere na consolidação de um projeto político pedagógico. Estes fatores ratificam a persistência do dilema secular de universalizar o ensino elementar.

Com a finalização deste artigo, esperamos que outros pesquisadores, com suas angústias do tempo presente, olhem ao passado, desta e de demais instituições londrinenses, e enriqueçam esta obra coletiva sempre a ser revisitada.

\section{REFERÊNCIAS:}

ABRAMO, M. A.; MUSILI, C. Semente do saber. In: Londrina puxa o fio da memória. Joinville: Letradágua, 2004. p. 57-58.

ALMEIDA, J. S. Mulheres na educação: missão, vocação e destino? A feminização do magistério ao longo do século XX. In: SAVIANI, D.; ALMEIDA, J. S.; SOUZA, R. F.; VALDEMARIN, V. T. O legado educacional do século XX no Brasil. 2. ed. Campinas, SP: Autores Associados, 2006. p. 59-107 (Coleção Educação Contemporânea).

ARIAS NETO, J. M. O eldorado: representações da política em Londrina, 1930/1975. Londrina: UEL, 1998. 308p.

BRASIL. Lei n. 5.692/71. Lei de diretrizes e bases da educação nacional. Disponível em < http://www.pedagogiaemfoco.pro.br/15692_71.htm>. Acesso em: 05 jun. 2010.

CANDOTTI, E. A. Memórias da cidade: Londrina 1930/1960. 1997. 191 f. Monografia (Especialização em História) - Universidade Estadual de Londrina, Londrina, PR, 1997.

CAPELO, M. R. C. Educação, Escola e Diversidade Cultural no meio rural de Londrina: quando o presente reconta o passado. 2000. 287f. Tese (Doutorado em Educação, Sociedade e Cultura) - Universidade Estadual de Campinas, Campinas, 2000.

FARIA, T. B. Em traços de modernidade: a história e a memória do Grupo Escolar “Hugo Simas" (Londrina-Pr, 1937- 1972). 2010. 188f. Dissertação (Mestrado em Educação) - Universidade Estadual de Maringá, Maringá, 2010. 
FARIA FILHO, L. M.; SOUZA, R. F. A contribuição dos estudos sobre grupos escolares para a renovação da história do ensino primário no Brasil. In: VIDAL, D. G. (Org.).

Grupos escolares: cultura escolar primária e escolarização da infância no Brasil (18931971). Campinas, SP: Mercado de Letras, 2006. p. 21-56.

GRANDOLFI, F. A.; LIMA, J. M.; SANTOS, R. Relatório final de estágio supervisionado I realizado no Colégio Estadual Hugo Simas. 2008. 38 f. Trabalho de Conclusão de Curso (Graduação em Arquivologia) - Universidade Estadual de Londrina, Londrina, PR, 2008.

KREUTZ. L. A educação de imigrantes no Brasil. In: LOPES, E. M. T.; FARIA FILHO, L. M. F.; VEIGA, C. G. (Orgs.). 500 anos de educação no Brasil. 2. ed. Belo Horizonte: Autêntica, 2000. p. 347-370. (Coleção Historial, 6).

LE GOFF, J. História e memória. Tradução de Bernardo Leitão [et al]. 5. ed. Campinas, SP: Ed. da Unicamp, 2003,. p. 525-539.

MAY, T. Pesquisa documental: escavações e evidências In: Pesquisa social: questões, métodos e processos. 3. ed. Porto Alegre: Artmed, 2004. p. 205-230.

MORTATTI, M. R. L. Os sentidos da alfabetização (São Paulo/ 1876-1994). São Paulo: Editora UNESP, 2000.

SCHELBAUER, A. R. Idéias que não se realizam: o debate sobre a educação do povo no Brasil de 1870 a 1914. Maringá, PR: EDUEM, 1998. 169p.

SOUZA, R. F. Templos de civilização: A implantação da escola primária graduada no Estado de São Paulo (1890-1910). São Paulo: Fundação Editora da UNESP, 1998.

\section{FONTES}

\section{DOCUMENTOS ESCRITOS}

COLÉGIO ESTADUAL HUGO SIMAS. Secretaria. Livro de ofícios de 1937 a 1941. Londrina, PR, 1937-1941. (Manuscrito).

COLÉGIO ESTADUAL HUGO SIMAS. Secretaria. Livro de matrícula de alunos 1940 a 1942. Londrina, $\mathrm{PR}, 1940-1942$. p. 16-59. (Manuscrito).

COLÉGIO ESTADUAL HUGO SIMAS. Secretaria. Livro ata de reunião pedagógica de 1941 e 1942. Londrina, PR, 1941-1942. (Manuscrito).

COLÉGIO ESTADUAL HUGO SIMAS. Secretaria. Livro de registro escolar: matrícula, professores e aparelhamento escolar de 1950 a 1952. Londrina, PR, 19501952. p. 159-160. (Manuscrito).

COLÉGIO ESTADUAL HUGO SIMAS. Secretaria. Diário de Classe de 1969. Londrina, PR, 1969b. (Manuscrito). 


\section{ICONOGRAFIA}

\section{COLÉGIO ESTADUAL HUGO SIMAS. A planta da construção do Grupo Escolar.} [193-]. 1 fotografia.

\section{COLÉGIO ESTADUAL HUGO SIMAS. Corpo docente do Grupo Escolar "Hugo Simas" e o Delegado do Ensino. [1945]. 1 fotografia}

\section{ENTREVISTAS}

COSENTINO, Yolanda Nella Voigt. Depoimento da ex-professora Yolanda Nella Voigt . Entrevistadora: Thais Bento Faria. Arquivo sonoro: 47min. 40s.; 11min. 55s. Entrevista concedida para a realização deste estudo em: 20 abr. 2009.

PENTEADO, Valderês Pereira. Depoimento da ex-professora Valderês Pereira Penteado. Entrevistadora: Thais Bento Faria. Arquivo sonoro: 27min. 18s.; 30min. 58s. Entrevista concedida para a realização deste estudo em: 25 abr. 2009.

PRATA, Sheila Navega de Souza. Depoimento da ex-professora Sheila Navega de Souza Prata. Entrevistadora: Thais Bento Faria. Arquivo sonoro: 42min. 57s.; 12min. 52s.

Entrevista concedida para a realização deste estudo em: 6 maio 2009.

SANTOS, Ruth Talarico Freitas dos. Depoimento da ex-professora Ruth Talarico Freitas dos Santos. Entrevistadora: Thais Bento Faria. Arquivo sonoro: 50min. 27s.; 19 min. 34s. Entrevista concedida para a realização deste estudo em: 28 abr. 2009.

Notas

\footnotetext{
${ }^{1}$ Artigo elaborado a partir de trabalho originalmente apresentado no VI Congresso Brasileiro de História da Educação, em 2011.

${ }^{2}$ Pedagoga da Secretaria de Educação do Estado do Paraná. Mestre em Educação pelo Programa de PósGraduação em Educação da Universidade Estadual de Maringá. E-mail: thasofia@ @otmail.com

${ }^{3}$ Professora Associada do Departamento de Teoria e Prática da Educação e do Programa de Pós-Graduação em Educação da Universidade Estadual de Maringá. E-mail: arschelbauer@uem.br

${ }^{4}$ Para maiores detalhes acerca da reconstrução da história e memória do Grupo Escolar "Hugo Simas", ver a Faria (2010).

${ }^{5}$ Grandolfi, Lima e Santos (2008) nos forneceram o "Relatório Final de Estágio Supervisionado I realizado no Colégio Estadual Hugo Simas", que possibilitou uma percepção do conjunto do acervo.

${ }^{6}$ Neste trabalho, empregamos o termo "moderno" embasado no estudo de Mortatti (2000), em que, ao ter como foco a história dos métodos de alfabetização no Brasil, verifica um culto ao "moderno" e uma insistente tensão entre o "antigo" e o "mais avançado" método de ensino. Por este motivo, menciona a estudiosa que, [...] talvez o melhor, portanto, seja pensar em modernidades [...]", porque o que era considerado "moderno" se torna "antigo" ao surgir um novo "moderno" (2000, p. 294).
}

Recebido em: $\quad 07.05 .12$

Aprovado em: $\quad 30.05 .12$ 